\title{
EDITORIAL
}

\section{Obscure Can be Supreme: A Double Lesson from the Stratospheric Ozone Shield}

$\mathrm{W}$ hen I was a young don at Oxford rather many years ago, my nearest neighbour where I lived* in wild, hilly surroundings a mere bicycling distance outside the University City was a physicist named G.M.B. Dobson, whose research involved sending balloons into the upper atmosphere to measure the ozone concentration at different levels or 'layers'. This periodical sending-up of balloons was, inter alia, to make wind measurements at the different levels, while he was also developing a special spectrophotometer to measure the ozone. That was the limit of my understanding as a mere biologist, and was practically all I could say to enquirers who would ask me what on earth my neighbour was doing with those balloons. And although it was too long ago to be sure of precisely what was said at the time, I do recall the gist of such remarks as 'how utterly useless', 'what a strange thing to do', and 'could anything be more pointless'.

Although I well remember visiting G.M.B. on occasion for coffee on Sunday mornings, I do not recall his ever mentioning the study of ultraviolet solar radiation penetration or any other specific reason for his balloons - chiefly that he was measuring the concentration of ozone as a trace-gas in the upper atmosphere. He was about 20 years my senior and we were fellows of different colleges - he of Merton and I of New College, founded respectively in $\mathrm{AD} 1264$ and 1379 - so that our conversations were probably about University rather than college micropolitics. Consequently I do not know but can only guess that he was concerned about what was I believe already widely recognized in scientific circles at the time and has latterly emerged as quite vitally important to life on Earth, namely the filtering-out effect of stratospheric ozone on harmful ultraviolet rays emanating from the Sun.

\section{Ozone Shield Vital but Threatened}

Fears of serious reduction in the effectiveness of this ozone shield were engendered some years ago with the discovery of a major 'hole' in it over Antarctica, since when the stratospheric ozone depletion has been observed to have increased and its area to have extended over much of the northern hemisphere. Thus in the first three months of this year there was a highly alarming stratospheric ozone decrease reported by NASA, the American National Aeronautics and Space Administration, over Europe and North America - to the lowest levels in the 37 years of ground-based measurements, according to our Geneva neighbour Dr Ruman D. Bojkov, Special Adviser on Ozone to both the World Meteorological Organization (WMO) and the United Nations Environment Programme (UNEP), and as kindly confirmed in Dr Bojkov's absence by the Deputy SecretaryGeneral of WMO, David N. Axford.

As was pointed out on the front page and elsewhere of a recent (23 April 1993) issue of a leading British newspaper, The Independent, the latest figures of stratospheric ozone depletion bring to the fore the broader lesson of showing that humanity has proved far more adept than seemed possible even a decade ago at altering the equilibrium of Planet Earth - which equilibrium has in turn proved quite alarmingly fragile in The Biosphere. Consequently when governments or major foundations or other deciding or funding agencies are presented in future with evidence, or even mere predictions, of major environmental problems, such as the 'greenhouse' effect or sea-level rising, and especially if stability of The Biosphere is in question, they would be wise to take a pessimistic view and act accordingly, or at least to listen and make sure the problem is studied intensively.

\section{Dobson Case a Striking Lesson}

To return in conclusion to the case of my erstwhile neighbour Dr G.M.B. Dobson, who regrettably died some years ago: the world now has the Dobson Unit and Apparatus for measuring stratospheric ozone and, through them and more modern devices and concomitant global campaigns, incipient realization of the quintessential need and responsibility to look after the life-preserving stratospheric ozone shield. For without it life on Earth and even in the ocean would be very adversely affected, to say the least.

This is clearly a striking, indeed double, lesson for us all concerning small or obscure beginnings and their conceivably infinite possibilities, and also concerning individuals and their sometimes supreme potentialities! Moreover we humans have the unique responsibility, ultimately to the entire Universe, of safeguarding life; for it now seems that there is nowhere else that life as we know it exists in, and emanates from, than Earth's Biosphere, which it is still surely in our own but no other living thing's power to safeguard and preserve.

\section{Nicholas Polunin \\ 26 April 1993 \\ Bellagio Study \& Conference Center Lake Como, Italy}

\footnotetext{
* In a wooden shack which I had built myself during World War II when Home Guard Sergeant and then Intelligence Officer in charge of Eastern and Central Oxford where locally we rather expected Hitler to strike; however, I am reminded by a correspondent that another rumour had it that Hitler had ordained that Oxford was not to be bombed as he planned to make the world-renowned 'city of dreaming spires' the capital of 'occupied England' - to which its relative immunity from bombing throughout World War II would seem to lend credence.
} 